\title{
POSITION OF CYANOBACTERIA AND ALGAE IN ORIGIN OF LIFE
}

\author{
Vishwanath Prasad \\ Department of Botany
}

\begin{abstract}
Our beautiful planet, the earth was originated 4.5 billion years ago in our solar system. Between $3.5-4.0$ billion years ago, after several events of chemical evolution and modification in the earth's atmosphere, the first life, amino acid and nucleic acid, called ecobiont or protobiont, was originated in abiogenesis phase and started protobiology phase. The life has evolved into three domains: age of Eobacteria, Cyanobacteria and Eukaryotes which ultimately evolve into land plants. The purpose of the this article is to add some recent information about origin of life and position of cyanobacteria in the evolution of higher plants.
\end{abstract}

\section{Keywords}

Origin, life, Ecobiont, Cyanobacteria, algae.

\section{Introduction}

Life is very mysterious gift of nature on this beautiful planet, earth. The origin of life and even earth in the universe is still mysterious and complex. The earth is a tiny part of the Universe. The theoretical rough estimate reveals that the universe consists about 50 billion galaxies. Astrophysics study of the universe from the earth using the art technology observation reveals the presence of two galaxies, elliptical and spiral, separated from each other by immense large empty space. Spiral galaxy, our closest neighbour called the Andromeda Nebula, located at about 28 million light years from the earth is the cluster of galaxies. Average galaxy consists of some 100 billion stars. Our sun is one of the middle size star and our earth is a middle size planet of the solar system (Carl Zeiss, 2005). The earth was probably formed about $4.5 \times 10^{9}$ years ago, however, the oldest terrestrial rocks found to date are about $3.5 \times 10^{9}$ years old or so. ( Margulis et al, 1976). 


\section{Origin of Life :}

Life probably originated when the earth's atmospherewasanoxicand consist of methane, ammonia, nitrogen and water vapour with preponderance of hydrogen (Oparin, 1964). Many events of chemical evolution are likely to have occurred in the prebiontic atmosphere, probably between 3500-400o million years ago and simpler organic compounds like amino acids were formed under the influence of ultraviolet radiations and electric discharge as sources of energy. Later, the earth cooled down sufficiently to provide pools of liquid water. In the early period of earth, there were production of complex organic compounds without life. It was called phase of abiogenesis.

Nature have made several trials in creating the first biological entity. The droplet called coacervates, may absorb water, swell and under go the processes of selectivity, recognition, interaction etc. It could have led to replicating molecules which gradually evolved into biological entities. This phage was the origin of amino acid which on heating originated nucleic acid. This phage is called eobiology (dawn of life ) or protobiology (first life). Thus, the organisms are accordingly called eobionts or protobionts. The eobionts and coacervates are the origin of biological organisms . Presently, the geological and biological evidences suggest that the first living forms on this planet were probably some heterotrophic anaerobic bacteria.

\section{Three - phases history of life}

Under two revolutionary periods, Glycobacterial revolution and Neomuran revolution (Cavalier - Smith, 2006), life has evolved into following three ages of life: age of Eobacteria , age of Cyanobacteria and age of Eukaryotes.

Age of Eobacteria

This first phase began before 2.9 -2.8 Gyrs ago when the origin of cells and anoxic photosynthesis generated the most primitive prokaryote chlorobacteria, the first negibacteria with cell bounded by two acyl ester phospholipid membranes. They have anoxygenic photosynthesis, chaemosynthesis using hydrogen or $\mathrm{H}_{2} \mathrm{~s}$ as hydrogen donor to fix carbon. Then, transition occurred in negibacteria, eurybacteria, posibacteria, glycobacteria and then into chlorobacteria with origination of flagella in cells. This is also called Chlorobacterial age. Archaea a third dormain of life, in addition to bacteria and eukaryote, on the basis of molecular, genomics and phylogenetic data is diversified into two major phyla, the Crenarchaeota and the Euryarchaeota. (Woese et. al., 1990; Gribaldo and Brochier, 2006)

\section{Age of Cyanobacteria}

After the Chlorobacterial or Eobacterial age, the cellular innovation and microbial radiation dramatically transformed the earth's surface and the glycobacterial revolution initiated an oxygenic age called age of Cyanobacteria. During this age, between 2.8 - 0.9 billion years ago, cyanobacterial photosynthesis predominantly fed ecosystem and the biosphere was differentiated into aerobic and anaerobic zones. Therefore, cyanobacteria are also called first oxygen producing organism and architects of atmosphere.

The Eobacteria and Cyanobacteria both have always two distinct lipid surface membranes where as posibacteria consists only one surface membrane, therefore, the Precambrian period could be properly termed as Age of Prokaryotes and the later half of this Eon, was the Age of cyanobacteria (Schopf, 20o6)

Unlike most other groups of bacteria, the cyanobacteria have a greater diversity of morphological phenotypewith few exceptions. Many cyanobacteria have exteremely long generation times as compared to the popular heterotrophic bacteria. They have efficient DNA-repair systems. The genome size is apparently larger in most complex cyanobacteria than Ecoli, Bacillus and smaller 


\section{Prasad}

unicellular cyanobacteria. The genome size of about 128 strains of cyanobacteria ranges from ca 1.6 billion daltons in unicellular type to 8.6 billion daltons in more complex filamentous type (Castenholz, 1992).

Proteins and nucleic acids are dividing fossils because they have been dynamically conserved by the evolutionary process over millions of years. The prebiontic atmosphere was highly reducing and hence hydrogenase, nitrogenase enzymes acetylene, cyanide, cyanogens, nitrites etc have high probability in cyanobacteria. They have a novel device, heterocysts, to protect the oxygen - labile nitrogenase. The cyanophycin granule in cyanobacteria contains equimolar proportions of arginine and aspartic acid. (Kumar, et. al., 1980)

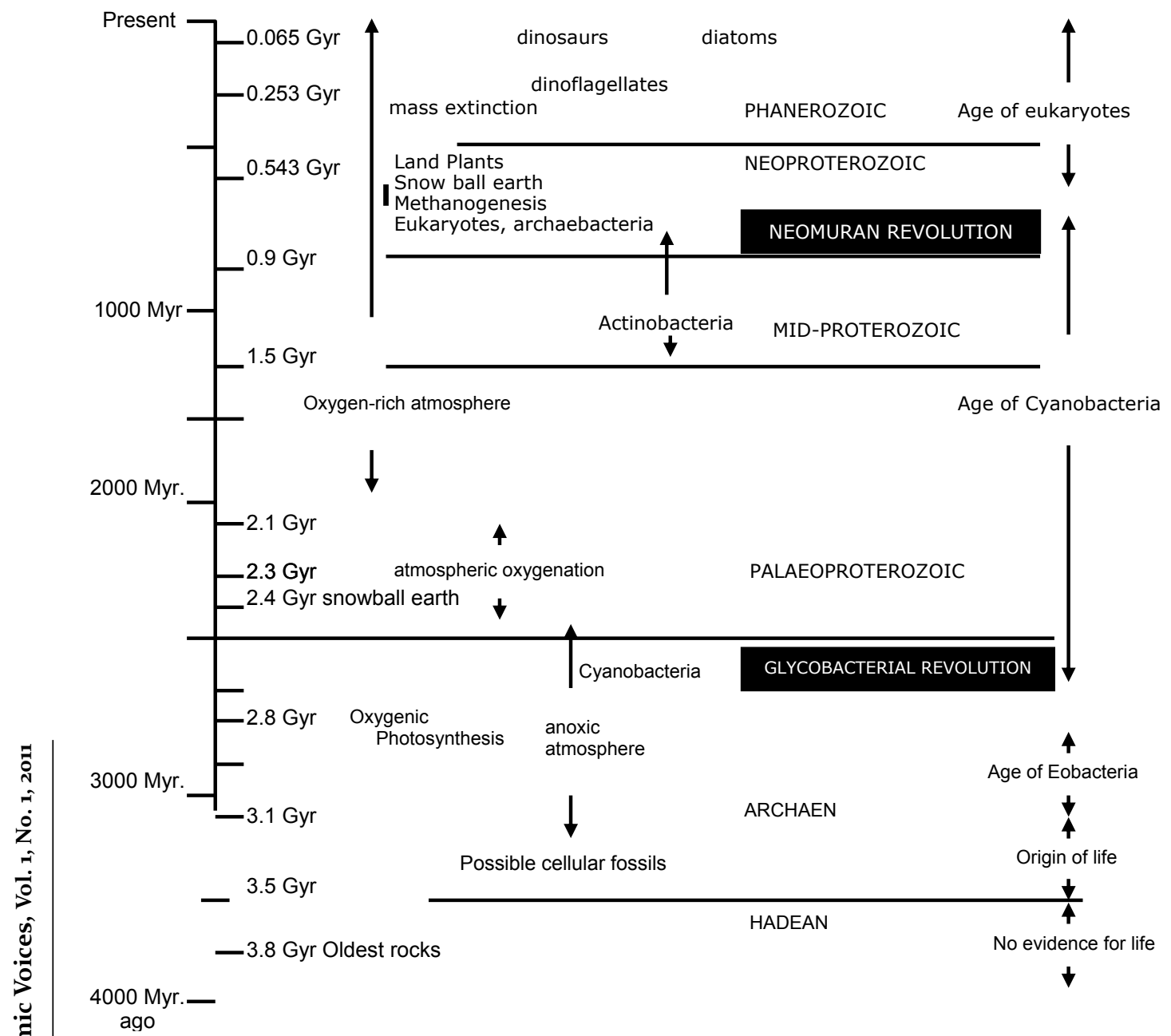

Fig 1. Origin of Life (Source : Cavalier - Smith, 2006)

(Gyr: Billion years; Myr: Million years ) 
Age of Eukaryote

The cyanobacterial oxygen liberation grew the ozone layer and later $0.9 \mathrm{Gyr}$ ago after rise of planktons, during Neomuran revolution another age started called age of Eukaryotes and Archaebacteria. During 720 Myr ago, due to ultraviolet, the Arachean organic carbon attributed methanogenesis and triggered snow ball Earth episode by slight global warming.

The evolution of green algal plastid is of cyanobacterial origin due to endosymbiosis which is supported by the discovery of the Prochlorophyta (Lewin, 1976). Cyanobacteria are the source of Glaucophyte simple plastids. The major lineages of the algae are the
Chlorophyta, Rhodophyta, Glaucophyta, Euglenophyta, Chlorarachniophyta, Haptophyta, Cryptophyta and Dinophyta. Now, the algae may be classified into 2 empires and 15 divisions (Prasad, 2010).

The eukaryotic phyla that exist today, have a fan-shaped phylogenetic evolution (Hoek et. al., 2009). From the green lineage diversification the Charophytes have originated. They have several similarities with land plants and initiated the evolution and development of terrestrial ecosystems including Bryophytes, Pteridophytes, and higher land plants (Kenrick and Crane, 1997; Bhattacharya and Medlin, 1998., Yin-lorg and Jaffery, 1999).
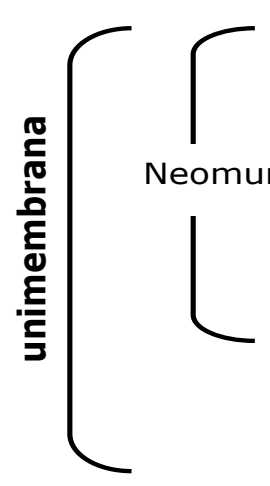

\section{Eukaryotes}

0.9 Gyr ago
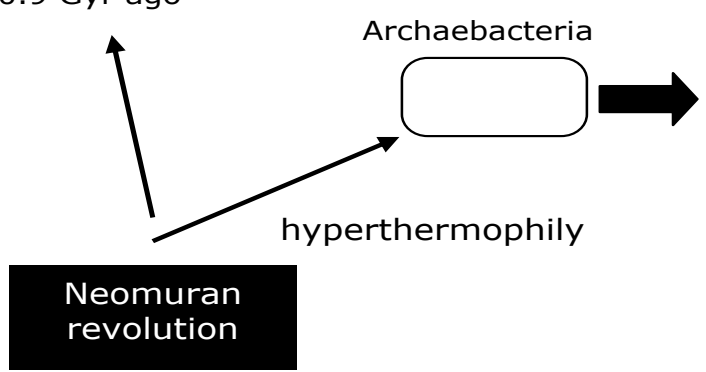

0.9 Gyr ago

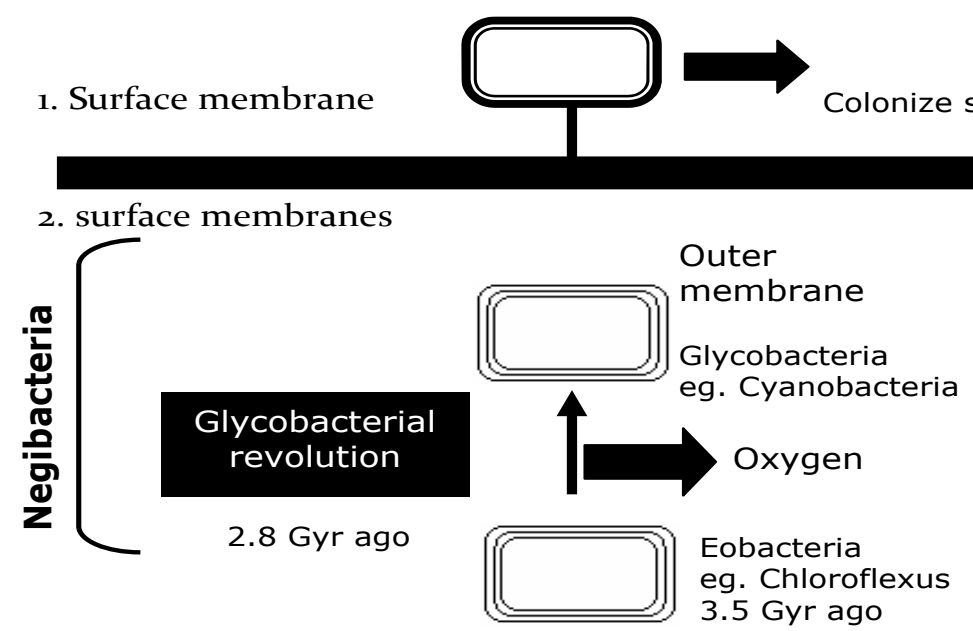

Fig 2. Tree of Life emphasizing major revolution (Source : Cavalier - Smith, 2006) 


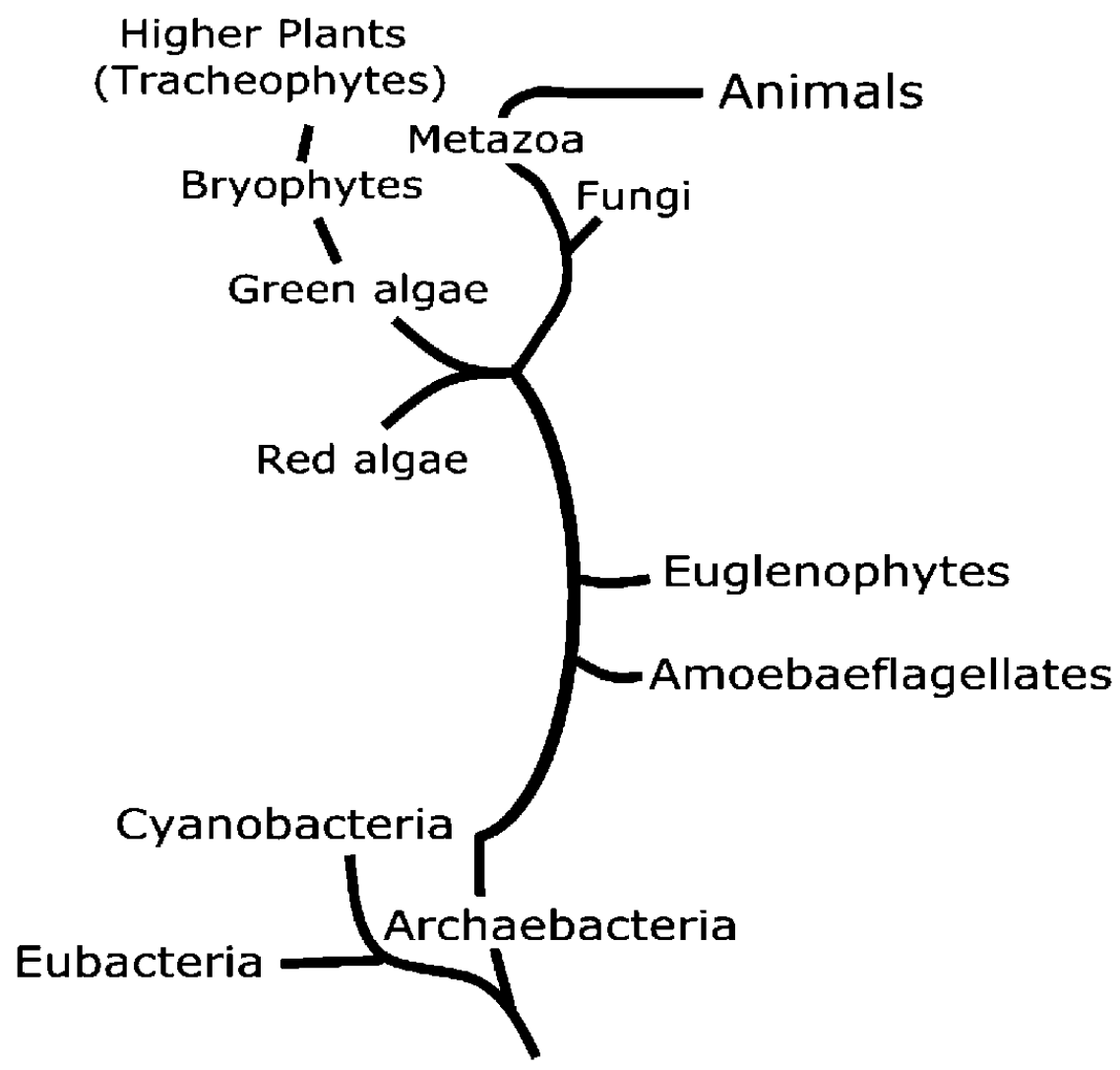

Fig 3. Tree of Life (Bhatacharya and Medlin, 1998; Hoek et. al., 2009)

\section{Conclusion}

First of all, life between 3.5-4.o billion years ago, originated in in abiogenesis phase in the form of amino acid and nucleic acid. The life has evolved into three domains: age of Ecobacteria, cyanobacteria and Eukaryotes. Cyanobacteria, first phototrophs, during glycobacterial revolution between 2.8-0.9 billion years ago, initiated the oxygenic age on the eareth. The started origin of prochlorphytes, glaucophytes and other mayor lineases of algae. The algae, especially charophytes initiated the evolution and development of the land plants.

\section{References}

Bhattacharya, D. \& Medlin, L. (1998). Algal Phylogeny and origin of Land Plants. Plant Physiol. 116, 9-15.

Carl Zeiss, A.G. (2005). Black Hole in the Holmberg II Galaxy. Innovation, 16,10-11.

Castenholz, R.W. (1992). Species usage, conceptand evolution in the cyanobacteria. J. Phycol. 28, 737-745.

Cavalier- Smith, T. (2006). Cell evolution and earth history: stasis and revolution. Phil. Trans. R. Soc. B. 361, 969-1006. 
Gribaldo, S. \& Brochier, A.C. (2006). The origin and evolution of Archaea: a state of the art. Phil. Trans. R. Soc. B. 361, 10071022.

Hoek, V. C. , Mann, D.G. \& Jahns, H. (2009). Algae : An introduction to Phycology. New Delhi: Cambridge University Press.

Kenrick, P. \& Crane, P. R. (1997). The Origin and early evolution of plants on land. Nature. 389, 33 - 39 .

Kumar, H.D., Kumar, A., Rai, L.C., Gour, G.P. \& Ahluwalia, A.S. (1980). Unique position of cyanobacteria in the continuum of Life. A paper presented in a workshop on 'Origin and Evolution of Life and intelligence in the Universe', Bhabha Atomic Research centre, Bombay, India.

Lewin, R.A. (1976). Prochlorophyta as a proposed new division of algae. Nature. 261, $9697-98$.
Margulis, L. , Walker, J.C.C. \& Rambler, M. (1976). Nature, 264, 620.

Oparin, A.I. (1964). The chemical origin of life. Ill: Spring field.

Prasad, V. (2010). Modern Phycology. Kathmandu : Heritage publishers and Distributor.

Schopf, J.W. (2006). Fossil evidence of Arachaen Life. Phil. Trans. R. Soc. B. 361, $869-885$.

Woese, C.R., Kandler, O. \& Wheelis, M.L. (1990). Towards a natural system of organisms: proposal for the domains Archaea, Becteria and Eukarya. Proc. Natl. Acad. Sci. . 87, 4576 - 4579.

Yin - Lorg, O. and Jaffery. D.P. (1999). Phylogeny of early land plants : Insight from genes and genomes. Trends in Plant Science. 4 (1), 25-30.

\section{The Author}

Vishwanath Prasad is an Associate Professor of Botany in Thakur Ram Multiple Campus, Birgunj where he has been teaching for the last thirty three years. He is a doctorate from the Banaras Hindu University (India). To his credit, he has published several articles in acclaimed national and international journals. His areas of interest include Algal Physiology, Algal Photobiology, UV-B and Climate Change. He is the Immediate Past President of Research Society of Integrated Sciences (RESIS), Birgunj and Chief Editor of Journal of Research Society of Integrated Sciences. He was one of the convenors of National Seminar on "Recent Advances in Plant Science in 2002(Birgunj).

Email: mpal_vp@yahoo.com 